\title{
Germectomy of Third Molars in Orthodontic Therapy: Usefulness of Volumetric Analysis with TC Cone Beam
}

\author{
Bisconte P*, Matarrese L, Del Rosso E, Farronato \\ G and Lombroni LG \\ Department of Orthodontics, Università degli Studi di \\ Milano, Italy \\ *Corresponding author: Bisconte P, Department \\ of Orthodontics, Università degli Studi di Milano, \\ Fondazione IRCCS Cà Granda - Ospedale Maggiore \\ Policlinico, Via della commenda 10 CAP: 20122 Milano \\ (MI), Italy
}

Received: July 20, 2017; Accepted: September 07, 2017; Published: September 26, 2017

\section{Abbreviations}

MRI: Magnetic Resonance Imaging; CBCT: Cone Beam Computed Tomography; CT: Computed Tomography; CB 3D: Cone Beam 3D; 38: Lower Left Third Molar; 48: Lower Right Third Molar

\section{Introduction}

Germectomy of lower third molars is a surgical intervention of choice in the presence of morphostructural or topographic alterations of dental germs or in the case of dysplastic disorders of the germ itself, such as follicular cases and neoplasms. Introduced in clinical practice around 1950 by Andersen, Germectomy is a surgical method that involves the removal of a dental organ with all its embryonic attachments when it is in the early stages of development and has not yet contracted with the adjacent anatomical structures $[1,2]$.

Dental medicine often has to deal with problems arising from the presence of third molar, often characterized by eruptions such as retention or inclusion (with oscillating rates ranging from $17 \%$ to $71.8 \%$ ) and problems arising to the difficult oral hygiene of this area. In some cases the problems are asymptomatic, in others there is local involvement (disodontiasis, cervical lesions, periodontal, rizolysis, follicular cysts, trigeminal neuralgia for compression of the lower alveolar nerve) or even systemic with septic phenomena [3].

Dental germ of the lower third molar is formed by anatomical and embryological characteristics posteriorly and obliquely or perpendicularly with respect to the second molar: the jaw in fact develops mainly behind and to the other, dragging in this path also the germ of the octave (curve Of Capdepont). These results in a frequent disodontiasis caused by anterior conditioning (second molar) and rear (front margin of the ascending jaw branch) [4-6].
Furthermore, third molars are also involved especially in the case of dental crowding, especially at the lower mandibular level. Just the need to avoid such conditions has led some authors to introduce the technique of Germectomy in the clinical field, sometimes considering it as a complement to orthodontic therapy itself to reduce the number of dental elements and favor a stable dental arch alignment [7].

The first surgical procedures among all the extraction of the wisdom tooth require exact knowledge of the anatomical structures. The CBCT (Cone Beam Computed Tomography) method offers diagnostic images on the three plans space exposing the patient to relatively low radiant doses. It offers many advantages over traditional $\mathrm{CT}$ in terms of reduced costs, accuracy, and practicality.

MRI can be used in cases that cannot be clarified in orthopantomography or computerized tomography to reduce the risk to the patient [8-10].

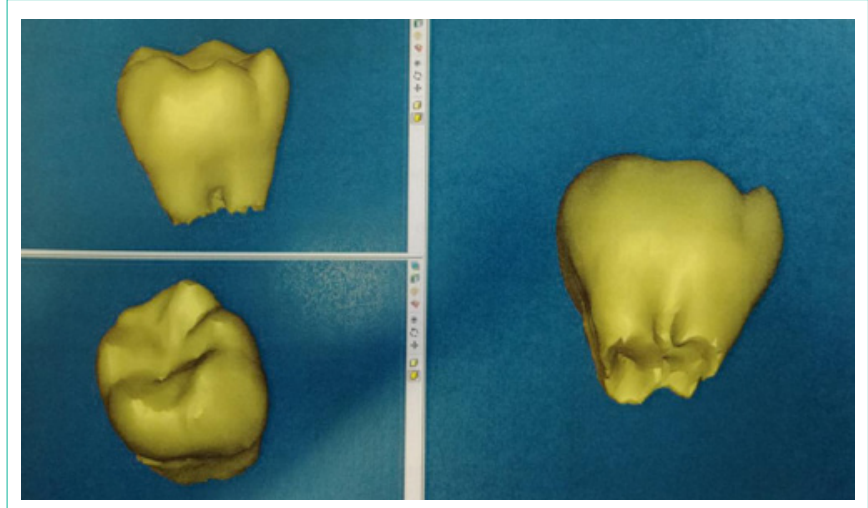

Figure 1: Volumetric analysis. 
Table 1: Males patients.

\begin{tabular}{|c|c|c|c|}
\hline age range (years) & volume volume $38\left(\mathrm{~mm}^{3}\right)$ & vovolume $48\left(\mathrm{~mm}^{3}\right)$ & Average bAverage between volumes 38 and $48\left(\mathrm{~mm}^{3}\right)$ \\
\hline $7-8$ & 12,29 & 19,80 & 16,05 \\
\hline $9-10$ & 163,34 & 156,49 & 159,92 \\
\hline $11-12$ & 327,75 & 350,71 & 339,23 \\
\hline $13-14$ & 415,37 & 378,7 & 397,03 \\
\hline $15-16$ & 682,32 & 631,98 & 657,15 \\
\hline $17-18$ & 808,8 & 786,12 & 797,46 \\
\hline $19-20$ & 1091,5 & 1119,33 & 1105,41 \\
\hline$>21$ & 834,05 & 780,29 & 807,17 \\
\hline
\end{tabular}

Table 2: Females patients.

\begin{tabular}{|c|c|c|c|}
\hline age rangage range (years) & vvolume $38\left(\mathrm{~mm}^{3}\right)$ & vvolume $48\left(\mathrm{~mm}^{3}\right)$ & Average bAverage between volumes 38 and $48\left(\mathrm{~mm}^{3}\right)$ \\
\hline $7-8$ & 95,34 & 108,22 & 101,78 \\
\hline $9-10$ & 202,27 & 170,29 & 186,28 \\
\hline $11-12$ & 284,46 & 316,66 & 300,56 \\
\hline $13-14$ & 442,91 & 397,47 & 420,19 \\
\hline $15-16$ & 559,28 & 577,68 & 568,48 \\
\hline $17-18$ & 645,28 & 616,74 & 631,01 \\
\hline $19-20$ & 783,7 & 810,88 & 797,29 \\
\hline$>21$ & 953,3 & 859,88 & 914,11 \\
\hline
\end{tabular}

\section{Materials and Methods}

Our institute with the assistance of $\mathrm{CB} 3 \mathrm{D}$ has conducted an investigation that has two purposes:

- to determine the best age of germectomy;

- to establish the correlations between the molar volume and the bone age of the patient.

92 patients were assessed, including 42 males (Table 1) (84 in total) and 50 females (Table 2) (99 in total). Patients were subjected to CBCT, visualization of scanned images was performed with Mimics software (Materialise, Leuven, Belgium). Thanks to the use of "Masks", the elements 38 and 48 of each patient were segmented, separating them from bone structures and adjacent teeth, then "3D Objects" were generated and their volume was calculated in cubic millimeters ( $\mathrm{mm} 3$ ) (Figure 1).

In Mimics, the region growing tool makes it possible to split the segmentation created by thresholding into several objects and to remove floating pixels.

Click the Region growing button or press Ctrl $+\mathrm{R}$. The mouse is now cross-shaped and the Region Growing window is on the screen.

Select the Source (= Green) and Target mask (= New Mask). Click the left mouse button on one point in the green area of the object of interest. The program starts to calculate the new segmentation; all points in the current segmentation object that are connected to the marked point will be used to form a new mask. The new segmentation is colored yellow.

Click the Close button to close the Region growing window.

To make this new mask active, select "Yellow" in the Visualization toolbar. Clicking on the green glasses will hide the green mask. Clicking the button again will make the green mask visible.

Check the mask on different images.

In the mask tab you see all created masks listed with their respective threshold. The names of these masks are Green and Yellow. Selecting one mask will make it active. Click on the Calculate 3D button [11].

For this study only the mineralized parts of the dental elements were taken into account, all the areas of the capsule of the elements in question were excluded. Patients were divided by sex and in 8 age ranges, starting at 7 years.

\section{Results and Discussion}

From the results obtained and from a thorough review of the literature we can affirm that:

7-8 years, 9-10 years: poor patient compliance, parental consent is not easy to obtain and difficulty in prognosis of third molar inclusion for poor development of the second molars and the presence of mixed dentition. These elements make it difficult to evaluate space discrepancy and there is no certainty of lack of space before the age of 11 years.

11-12 years: According to Merlini [12], the age range of 1112 years is not recommended for Germectomy because there is an incomplete second molars eruption that would cause problems in flap surgery.

13-14 years: it appears as the best age for Germectomy, as the second molars eruption occurred, the patient's compliance increased and the dental volume allows for minimally invasive surgery. 
$>15$ years: increased dental volumes that cause invasive surgery.

Literature is still open about the age most suited to practicing third molars Germectomy, the opinions of the various authors are discordant, varying from 8 to 16 years and, in certain situations, even after 18 years [13-16].

As far as bone age is concerned, we are still unable to perform accurate evaluations and our study needs further insights.

\section{Conclusion}

In general, the avulsion of the germs of the third molars must be much earlier, the more they constitute an impediment to the orthodontic action of a certain treatment and when the greater is presumed to be the lack of space, and in cases of considerable dental-alveolar discrepancy, both in cases where the space is further sacrificed by orthodontic procedures distalizing the molars.

\section{References}

1. Andreasen N. Ortopedia funzionale dei mascellari. Soc Ed Libraria Milano. 1956.

2. Bjork $A$, Svendsen $H$, Malmskov O. Prediction of lower third molar impaction from the frontal cephalometric projection. Eur J of Orthod. 1985; 7: 1-16.

3. Haavikko K, Altonen M, Mattila K. Predicting angulational development and eruption of the lower third molar. Cit. da Pappalardo G, Caltabiano M, Cicciù D. 1985.

4. Ricketts RM. Studies leading to the practice of abortion of lower third molar. Dental Cl of North Am. 1979; 23: 393-411.

5. Garattini G, Sacilotto GL, Strohmenger L, Laura, Weinstein, Roberto Lodovico. Germectomia dei terzi molari inferiori. Indicazioni e controindicazioni. DentalCadmos. 1988; 56: 40-44.
6. Gennari U, Cozzani G. Le indicazioni e la tecnica della germectomia degli ottavi. Cit da Merlini C, Gallini G, Canzi D. Mondo Ortod. 1983; 48: 25-38, Angle Orthod. 1978; 48:39-48.

7. Belleggia F, Ricci S, De Luca M, Gargari M, Arcuri C. La germectomia dei terzi molari inferiori. Italian Oral Surgery. 2006; 3:19-28.

8. Nessi R, Leonida A. Introduzione alla radiologia implantologica. Bologna: Ed Martina. 2008.

9. Nessi R, Vigano L. Radiologia odontostomatologica. Padova: Ed Piccin 2004.

10. Scarfe WC. Clinical application of Cone Beam computed tomography in dental practice. J Can Dent Assoc 2006; 72: 75-80.

11. Mimics 9 Reference Guide - SPL Massmail Services. 2010.

12. Merlini C, Gallini G, Canzi D. II momento giusto per eseguire una germectomia precoce. Mondo Ortod. 1983; 8: 41-46.

13. Farronato G, Garagiola U, Farronato D, Bolzoni L, Parazzoli E. Temporary lip paresthesya during orthodontic molar distalization: report of a case. Am J Orthod. Dentofacial Orthop. 2008; 133: 898-901.

14. Osborn TP, Frederickson GC, Small IR, Torgenson TS. A prospective study of complications related to mandibular third molar surgery. J Oral Maxillofac surg 1985; 43: 767-769

15. Chiapasco M, Crescentini M, Romanoni G. Estrazione dei terzi molari inferiori: germectomia o avulsione tardiva? Minerva Stomatologica. 1994; 43 191-198.

16. Richardson ME. Development of the lower third molar from 10 to 15 years. Angle Orthod. 1973; 43: 191-193.
Austin J Radiol - Volume 4 Issue 3 - 2017

ISSN : 2473-0637 | www.austinpublishinggroup.com

Bisconte et al. (C) All rights are reserved
Citation: Bisconte P, Matarrese L, Del Rosso E, Farronato G and Lombroni LG. Germectomy of Third Molars in Orthodontic Therapy: Usefulness of Volumetric Analysis with TC Cone Beam. Austin J Radiol. 2017; 4(3): 1072. 